\title{
DOES THE ADAMKIEWICZ ARTERY ORIGINATE FROM THE LARGER SEGMENTAL ARTERIES?
}

Tokuo Koshino, MD

Gen Murakami, MD

Kiyofumi Morishita, MD $^{\text {a }}$

Tohru Mawatari, MD

Tomio Abe, MD
Objective: The Adamkiewicz artery supplies most of the blood to the anterior spinal artery, which perfuses the anterior two thirds of the spinal cord. During operations for thoracoabdominal aortic aneurysm, detailed anatomic knowledge of the Adamkiewicz artery and its correlation with the intercostal and/or lumbar arteries is important to prevent postoperative paraplegia. Methods: Minute dissection was performed on 102 formol-fixed adult cadavers without any history of circulatory disorders. The Adamkiewicz artery was found in the epidural space after laminectomy of the vertebrae. The entire course between the Adamkiewicz artery and the intercostal and/or lumbar artery was dissected carefully. The vertebral level, laterality, and mean diameter of all Adamkiewicz arteries were investigated. The correlation between the diameter of the Adamkiewicz artery and that of the intercostal and/or lumbar arteries was also determined. Results: The mean number of Adamkiewicz arteries per cadaver was $1.3 \pm 0.65$, and the mean diameter was $0.77 \pm 0.24 \mathrm{~mm}$ (range, 0.50 to $1.49 \mathrm{~mm}$ ). Approximately $70 \%$ of the Adamkiewicz arteries originated from the intercostal and/or lumbar arteries on the left side, frequently at the T8-L1 vertebral level. There was no statistically significant correlation between the diameter of the Adamkiewicz artery and that of intercostal and/or lumbar arteries. Conclusion: This study provides evidence that, during operations on the thoracoabdominal aorta, the intercostal and/or lumbar arteries should be preserved, regardless of their diameter, to prevent postoperative paraplegia. (J Thorac Cardiovasc Surg 1999;117:898-905)
$\mathrm{T}_{\mathrm{i} \text { is }}^{\mathrm{h}}$ he Adamkiewicz artery (arteria radicularis magna) is thought to deliver most of the blood to the thoracic and lumbar spinal cord. ${ }^{1-3}$ During replacement and reconstructive surgery of the thoracoabdominal aorta, vascular surgeons have to reconstruct the intercostal artery (ICA) and lumbar artery (LA) to maintain the blood flow through the Adamkiewicz artery, which originates from the ICA/LA. The problem as to which ICA/LA should be reconstructed remains controversial; some surgeons reconstruct all ICA/LAs within a limited level (eg, T8 to and including L1) ${ }^{4}$; others recon-

From the Department of Thoracic and Cardiovascular Surgery and

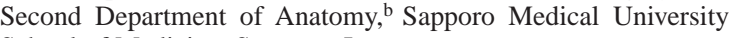
School of Medicine, Sapporo, Japan.

Received for publication Jan 28, 1998; revisions requested Jan 30, 1998; revisions received Jan 6, 1999; accepted for publication Jan $11,1999$.

Address for reprints: Tokuo Koshino, MD, Department of Thoracic and Cardiovascular Surgery, Sapporo Medical University School of Medicine, South 1 West 16, Chuo-ku, Sapporo 060-8543, Japan.

Copyright (C) 1999 by Mosby, Inc.

$0022-5223 / 99 \$ 8.00+0 \quad \mathbf{1 2 / 1 / 9 7 0 5 1}$ struct the ICA/LAs with a larger diameter before the smaller ones. ${ }^{5}$ In the latter case, surgeons seem to consider that wide ICA/LAs take priority over narrow ICA/LAs based on the assumption that a wide Adamkiewicz artery, which is more effective at supplying the spinal cord, emerges from a wide ICA/LA. The aim of this study was to clarify the correlation between the diameter of the ICA/LA and the diameter of the Adamkiewicz artery to establish the basis for choosing the ICA/LA that should be reconstructed.

\section{Materials and methods}

Materials. Minute dissection was performed on 102 donated Japanese adult cadavers (50 male and 52 female), with no history of obvious circulatory disorders. In 12 of the 102 formol-fixed cadavers, acrylic polymer red dye (Liquitex; Bonny, Tokyo, Japan) was injected with high pressure through the femoral artery immediately after fixation to identify the radicular artery and anterior spinal artery. There was no difference in diameter of the Adamkiewicz arteries in the cadavers that were injected with dye compared with the others. In the injected cadaver, the connection between the anterior spinal artery and the Adamkiewicz artery could easily be observed. 

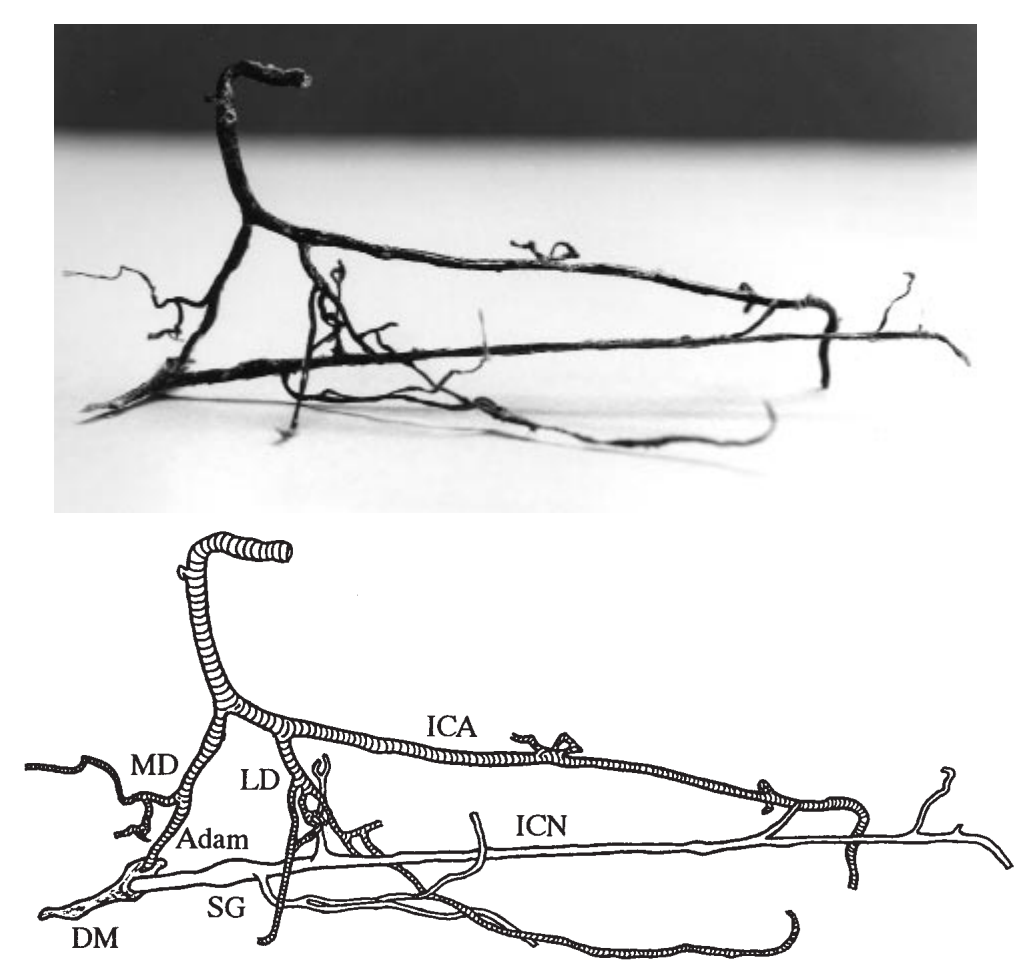

Fig 1. Photograph shows the connection of the Adamiewicz artery and the medial dorsal branch of the ICA originated from the ICA as a single stem and then divided separately. The medial dorsal branch of the ICA runs posteriorly to supply blood to the back muscles. Adam, Adamkiewicz artery; ICA, intercostal artery; ICN, intercostal nerve; $M D$, medial dorsal branch of the ICA; $L D$, lateral dorsal branch of the ICA; $S G$, spinal ganglion; $D M$, dura mater.

Exposure of the Adamkiewicz artery and ICA/LA. The cadavers were placed in the prone position, and the Adamkiewicz arteries were located in the epidural spaces after laminectomy of the vertebrae. The cadavers were then moved to the supine position, and the ICA/LAs were dissected between the fifth thoracic and second lumbar vertebral level. The connections between the Adamkiewicz arteries and ICA/LAs were also dissected to determine where the Adamkiewicz arteries originated (Fig 1).

Measurement of the diameter of the Adamkiewicz arteries and ICA/LAs. The vertebral level and laterality of the Adamkiewicz arteries were investigated. The diameter of the Adamkiewicz artery was measured with a digimatic caliper (Mitutoyo Co, Kawasaki, Japan) immediately after it perforated the dural sac with no distention. Before measurement, it was confirmed that the Adamkiewicz artery was connected to the anterior spinal artery in the dural sac. The form of the connection between them was not examined in this study. Although a fine arterial twig ( $<0.5 \mathrm{~mm}$ in diameter) was frequently observed along the spinal nerve roots, we considered that a spinal branch of more than $0.5 \mathrm{~mm}$ in diameter at the fifth thoracic to the second lumbar vertebral level was the "effective" Adamkiewicz artery according to previous anatomic and angiographic reports. ${ }^{6-13}$ Measurement of these fine twigs was difficult and was not always accurate. The out- side diameter of the ICA, including the upper LA, was measured immediately after its origin from the aorta.

Statistical analysis. All values are expressed as the mean \pm SD. Data were processed with the StatView J-4.5 software (Abacus Concepts Inc, Berkeley, Calif). The correlation between the diameter of the Adamkiewicz artery and that of the ICA/LA was examined by a simple linear regression test.

\section{Results}

Number of Adamkiewicz arteries per cadaver. The number of Adamkiewicz arteries was determined in 90 of the 102 cadavers (88\%). Only 1 Adamkiewicz artery was found in 67 of the 90 cadavers $(74 \%)$, whereas more than 2 Adamkiewicz arteries were found in each of the other 23 cadavers (26\%). A total of 120 Adamkiewicz arteries were therefore recorded (mean per cadaver, $1.3 \pm 0.65$ ). This mean number of Adamkiewicz arteries per cadaver is smaller than that in previous reports, ${ }^{10,11}$ which might be the result of our decision to select the relatively large radicular artery as the Adamkiewicz artery. In those cases in which 2 Adamkiewicz arteries were observed, the relationship of the vertebral level is shown in Fig 2. 


\section{Vertebral level}

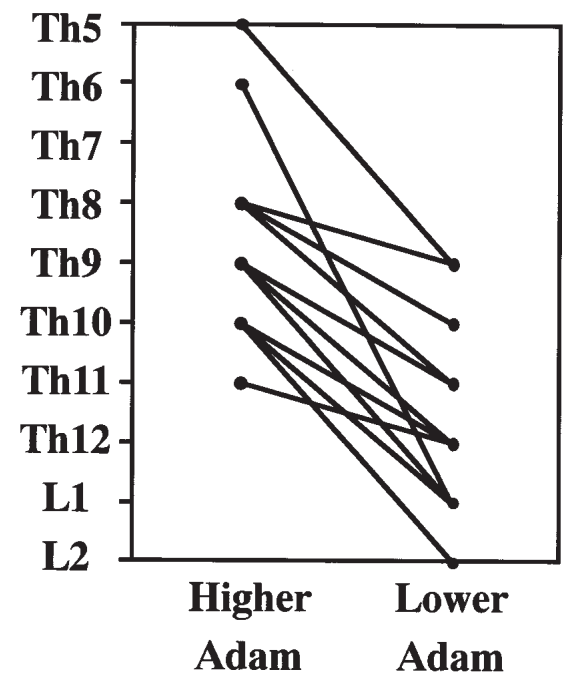

Fig 2. Relationship of the vertebral level in cadaver in which 2 Adamkiewicz arteries (Adam) were observed.

Laterality of the Adamkiewicz arteries. Of the 120 Adamkiewicz arteries identified, 86 (72\%) originated from the ICA/LA on the left side, and 34 (28\%) progomated on the right side (Fig 3). In the 23 cases where more than 2 Adamkiewicz arteries were identified, the Adamkiewicz arteries originated unilaterally in 13 cadavers $(57 \%)$ and bilaterally in 10 cadavers (43\%). According to our results, the Adamkiewicz arteries showed a left-sided predominance, which agrees with previous reports. ${ }^{6-10}$

Vertebral level of the Adamkiewicz arteries. The bilateral incidence of the Adamkiewicz artery arose from the fifth thoracic (T5) ICA in 2\%, T6 in 2\%, T7 in 3\%, T8 in 5\%, T9 in 19\%, T10 in 23\%, T11 in 25\%, $\mathrm{T} 12$ in $12 \%$, the first LA (L1) in $8 \%$, and L2 in $3 \%$ of cases (Fig 3). Thus the Adamkiewicz artery frequently (91\%) originated between the T8 and L1 vertebral levels. Overall, these vertebral levels correspond to those of previous reports. ${ }^{6,8}$

Diameter of the Adamkiewicz arteries. The diameter of the 120 Adamkiewicz arteries examined ranged from 0.50 to $1.49 \mathrm{~mm}$, with a mean of $0.77 \pm 0.24 \mathrm{~mm}$. The mean diameter of the Adamkiewicz arteries emerging from the left side was $0.76 \pm 0.23 \mathrm{~mm}$ and from the right side was $0.76 \pm 0.26 \mathrm{~mm}$. This difference was not significant $(P=.8)$. The mean diameter of the Adamkiewicz arteries at each vertebral level is shown in Table I. The mean diameter of all of the Adamkiewicz arteries and of the Adamkiewicz arteries at each vertebral level were compared statistically, and
Table I. The mean diameter of the Adamkiewicz artery at each vertebral level

\begin{tabular}{lc}
\hline Level & Average diameter $(\mathrm{mm})$ \\
\hline T5 & $0.64 \pm 0.09$ \\
T6 & $0.67 \pm 0.03$ \\
T7 & $0.76 \pm 0.47$ \\
T8 & $0.61 \pm 0.22$ \\
T9 & $0.76 \pm 0.22$ \\
T10 & $0.75 \pm 0.21$ \\
T11 & $0.83 \pm 0.29$ \\
T12 & $0.69 \pm 0.19$ \\
L1 & $0.87 \pm 0.26$ \\
L2 & $0.76 \pm 0.19$ \\
\hline
\end{tabular}

no significant difference was found. These results relating to diameter confirm previous data from studies in white ${ }^{14}$ and in Japanese subjects. ${ }^{15}$

Correlation between the diameter of the Adamkiewicz arteries and the ICA/LAs. In 44 of the 90 cadavers in which Adamkiewicz arteries were identified, further anatomic dissection was performed to examine the ICA/LAs. Forty-eight Adamkiewicz arteries were present in these 44 cadavers, and the ICA/LAs from which they arose were exposed along their entire course. The diameter of the ICA/LAs at the T5 to L2 vertebral level ranged from 1.42 to $4.58 \mathrm{~mm}$ (mean, $2.8 \pm$ $0.66 \mathrm{~mm}$ ). This diameter was approximately the same as that of the ICA/LAs from which the Adamkiewicz arteries originated (1.57-4.34 mm; mean, $3.0 \pm 0.69 \mathrm{~mm}$ ).

The results of the statistical analysis of the correlation between the diameter of the Adamkiewicz arteries and of their original ICA/LAs at the T5 to L2 vertebral level are shown in Fig 4. As can be seen, the diameter of the Adamkiewicz arteries ranged from 0.50 to 1.32 $\mathrm{mm}$, although that of the ICA/LAs ranged from 1.57 to $4.34 \mathrm{~mm}$. There was no significant correlation between the diameter of the Adamkiewicz artery and that of the ICA/LA from which the Adamkiewicz artery originated $(r=0.255 ; P=.08)$. When the maximum and minimum diameters of the Adamkiewicz arteries and ICA/LAs were compared, however, a marked relationship was noted. When the ICA was $1.57 \mathrm{~mm}$ (minimum) in diameter, the Adamkiewicz artery was 1.32 $\mathrm{mm}$ in diameter. When the ICA was $4.34 \mathrm{~mm}$ (maximum) in diameter, the Adamkiewicz artery was only $0.50 \mathrm{~mm}$ (minimum) in diameter. Furthermore, within the T8 to L1 vertebral level, the diameter of the ICA/LA varied considerably and did not correlate with that of the Adamkiewicz artery. Consequently, it was noted that a narrow Adamkiewicz artery possibly emerged from a wide ICA/LA and vice versa. 


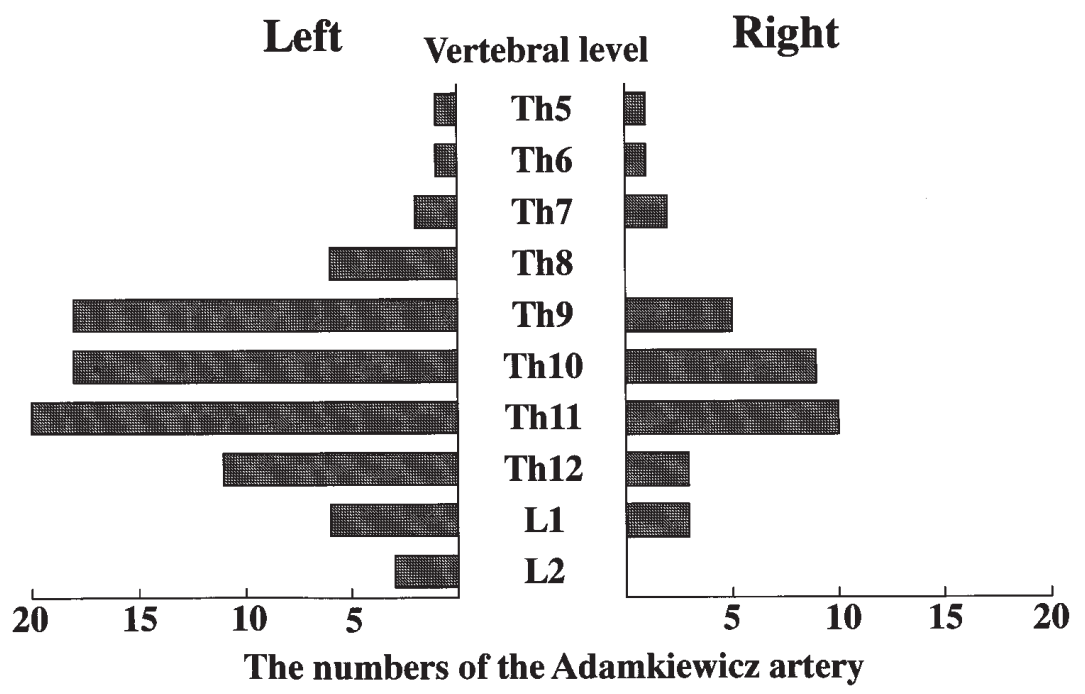

Fig 3. Frequency of vertebral level termination and laterality of 120 Adamkiewicz arteries in 90 cadavers. The Adamkiewicz artery frequently originated from ICA/LA between the eighth thoracic and first lumbar vertebral level on the left side.

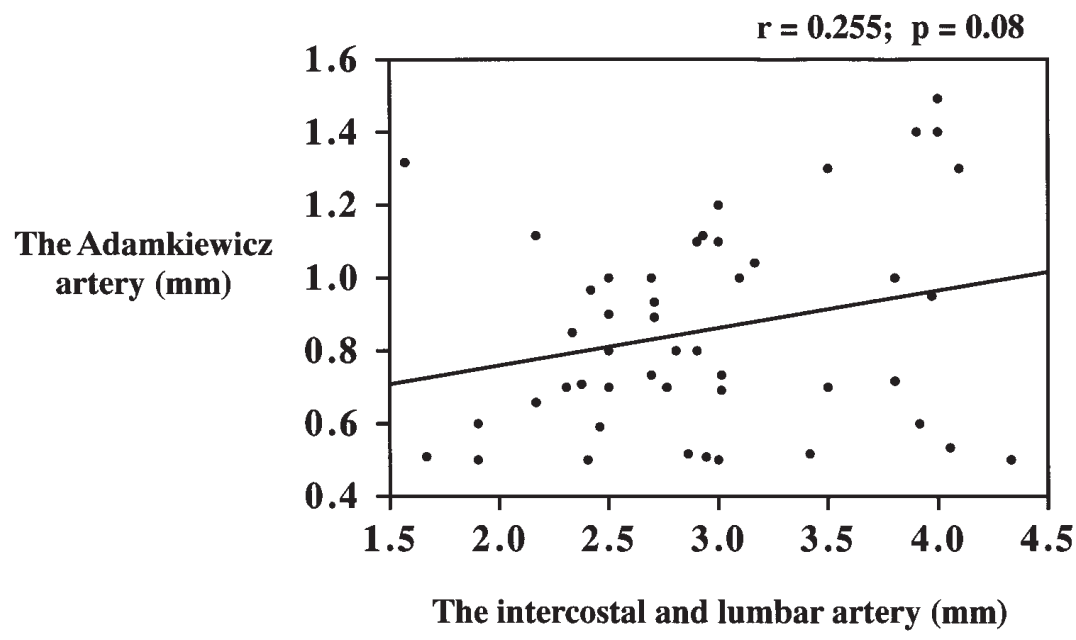

Fig 4. Correlation between the diameter of the Adamkiewicz artery and of the ICA/LA, which existed between the fifth thoracic and second lumbar vertebral level. No significant correlation was observed between them.

\section{Discussion}

The results of the present study demonstrate that, in most cases, the size of the ICA/LA does not correspond to that of the Adamkiewicz artery. Thus reconstruction of a wide ICA/LA does not necessarily ensure the maintenance of the spinal blood supply through the Adamkiewicz artery. Therefore the question of which ICA/LA should be reconstructed during aortic replacement operation should be asked. On the basis of the results of this study, we recommend that all ICA/LAs within a given level (eg, T8-L1) ${ }^{4,16}$ should be pre- served. Although many surgeons have already pointed out the importance of preserving the lower thoracic ICAs and upper LAs to prevent postoperative paraplegia, ${ }^{17,18}$ we suspect that some surgeons do not always reconstruct all lower ICAs and upper LAs but reconstruct only the larger ICA/LAs.

According to the law of Hagen-Poiseuille, blood flow volume per time $=\partial \times$ diameter $^{4} /$ length of vessel (ie, blood flow through a vessel $1.0 \mathrm{~mm}$ in diameter is 16 times greater than that through a vessel $0.5 \mathrm{~mm}$ in diameter, with the assumption that these lengths are 
almost equal). Thus the diameter of the ICA/LA and that of the Adamkiewicz artery are the most critical factors for blood supply to the spinal cord. The larger amount of blood supplied through a wide ICA/LA, however, did not always seem to depend on the demand from the spinal cord but on that of other tissues such as the back muscles, although muscular branches were not measured in this study.

Overall, the present results confirm our working hypothesis that all lower ICAs and upper LAs should be preserved, even if they are narrow.

\section{Study limitation}

In the present study, the large numbers of cadavers examined gives us considerable confidence that our data regarding the distribution, laterality, and diameter of the Adamkiewicz artery are reliable. However, in this study, we investigated the correlation between the diameter of the Adamkiewicz artery and of the ICA/LA using adult cadavers without aneurysmal change of the aorta or aortic dissection. In patients with thoracoabdominal aortic aneurysms or aortic dissections, the functional relationship between the ICA/LA and Adamkiewicz artery seems to be more complicated. It is possible that occlusion of the ICA/LA that emerged from the Adamkiewicz artery might occur as a result of atherosclerotic change. Consequently, radicular arteries less than $0.5 \mathrm{~mm}$ in diameter may play an important role in supplying blood to the spinal cord. The Adamkiewicz arteries identified anatomically in this study therefore may not always coincide with the Adamkiewicz arteries that are functionally effective clinically. Furthermore, the role of the collateral circulation between the radicular arteries is not clear. In our dissections, we could not identify the collateral vessels; previous angiographic reports have shown them to be extremely thin. ${ }^{19-22}$ Ideally, more detailed anatomic studies of the circulation to the spinal cord will unveil some of these factors that are important in preventing postoperative paraplegia after operations on the thoracoabdominal aorta.

During operations for thoracoabdominal aortic aneurysm or aortic dissection, we have routinely reconstructed the intact ICA/LAs within the T8 to L1 vertebral level to maintain the blood supply to the spinal cord, thinking that the Adamkiewicz artery originated from one of these levels. On the basis of the data from this study, however, we believe that more general and complete reconstruction of the ICA/LAs, regardless of their diameter, could reduce the incidence of postoperative paraplegia. This hypothesis is likely to form the basis of our working strategy from now on.
We are grateful to the following persons for use of materials: Professor T. Nakao (Akita University School of Medicine), Professor H. Kiyama (Asahikawa Medical College), Professor J. Kodama (Hokkaido University School of Medicine), and Professor Y. Inoue (Hokkaido University School of Medicine).

\section{REFERENCES}

1. Adamkiewicz A. Die Blutgefässe des menschlichen Rückenmarkes. I. Die Gefässe der Rückenmarkssubstanz. Sitzungsberichte der kais. Akademie der Wissenschaften zu Wien. Math.-Naturwissenschaftl. Classe 1881;84:469-502.

2. Adamkiewicz A. Die Blutgefässe des menschlichen Rückenmarkes. II. Die Gefässe der Rückenmarkesoberfläche. Sitzungsberichte der kais. Akademie der Wissenschaften zu Wien. Math.-Naturwissenschaftl. Classe 1882;85:101-30.

3. Kadyi H. Über die Blutgefässe des menschlichen Rückenmarkes. Anat Anz 1886;1:304-14.

4. Svensson LG, Crawford ES, Hess KR, Coselli JS, Safi HJ. Experience with 1509 patients undergoing thoracoabdominal aortic operation. J Vasc Surg 1993;17:357-68.

5. Kouchoukos NT, Rokkas CK. Descending thoracic and thoracoabdominal aortic surgery for aneurysm or dissection: How do we minimize the risk of spinal cord injury? Semin Thorac Cardiovasc Surg 1993;5:47-54.

6. Romanes GJ. The arterial blood supply of the human spinal cord. Paraplegia 1965;2:199-206.

7. Doppman J, Di Chiro G. The arteria radicularis magna: radiographic anatomy in the adult. Br J Radiol 1968;41:40-5.

8. Tveten L. Spinal cord vascularity. III. The spinal cord arteries in man. Acta Radiol 1976;17:257-73.

9. Svensson LG, Klepp P, Hinder RA. Spinal cord anatomy of the baboon: comparison with man and implications for spinal cord blood flow during thoracic aortic cross-clamping. S Afr J Surg 1986;24:32-4

10. Schalow G. Feeder arteries, longitudinal arterial trunks and arterial anastomoses of the lower human spinal cord. Zentralbl Neurochir 1990;51:181-4.

11. Rodriguez-Baeza A, Muset-Lara A, Rodriguez-Pazos M, Domenech-Mateu JM. The arterial supply of the human spinal cord: a new approach to the arteria radicularis magna of Adamkiewicz. Acta Neurochir 1991;109:57-62.

12. Kieffer E, Richard T, Chiras J, Godet G, Cormier E. Preoperative spinal cord arteriography in aneurysmal disease of the descending thoracic and thoracoabdominal aorta: preliminary results in 45 patients. Ann Vasc Surg 1989;3:34-46.

13. Williams GM, Perler BA, Burdick JF, Osterman FA Jr, Mitchell $\mathrm{S}$, Merine D, et al. Angiographic localization of spinal cord blood supply and its relationship to postoperative paraplegia. J Vasc Surg 1991;13:23-33.

14. Suh TH, Alexander L. Vascular system of the human spinal cord. Arch Neurol Psychiatr 1939;41:659-77.

15. Goto N, Shiraishi N. Morphology of arteria radicularis magna anterior et posterior. Sekitui-sekizui 1988;1:427-33.

16. Coselli JS. Thoracoabdominal aortic aneurysms: experience with 372 patients. J Card Surg 1994;9:638-47.

17. Cox GS, O'Hara PJ, Hertzer NR, Piedmonte MR, Krajewski LP, Beven EG. Thoracoabdominal aneurysm repair: a representative experience. J Vasc Surg 1992;15:780-7. 
18. Grabenwöger M, Ehrlich M, Simon P, Grimm M, Laufer G, Wollenek G, et al. Thoracoabdominal aneurysm repair: spinal cord protection using profound hypothermia and circulatory arrest. J Card Surg 1994;9:679-84.

19. Di Chiro G, Wener L. Angiography of the spinal cord: a review of contemporary techniques and application. J Neurosurg 1973;39:1-29.

20. Fereshetian A, Kadir S, Kaufman SL, Mitchell SE, Murray RR, Kinnison ML, et al. Digital subtraction spinal cord angiography in patients undergoing thoracic aneurysm surgery. Cardiovasc Intervent Radiol 1989;12:7-9.

21. Savader SJ, Williams GM, Trerotola SO, Perler BA, Wang MC, Venbrux AC, et al. Preoperative spinal artery localization and its relationship to postoperative neurologic complications. Radiology 1993;189:165-71.

22. Heinemann MK, Brassel F, Herzog T, Dresler C, Becker H, Borst HG. The role of spinal angiography in operations on the thoracic aorta: myth or reality. Ann Thorac Surg 1998;65:346-51.

\section{Commentary}

A thorough understanding of spinal cord vascular anatomy is of particular importance in the prevention of postoperative spinal cord injury after aortic surgery. ${ }^{1,2}$ The spinal cord is supplied by both anterior (larger) and posterior (smaller) radicular arteries arising from segmental intercostal or lumbar arteries, with an average of 2 to 4 thoracic radicular arteries arising from the intercostals in primate adults. ${ }^{1,3}$ The lumbar area has 2 to 3 lumbar radicular arteries, whereas the distal end of the cord is supported by a cruciate anastomosis. These radicular arteries supply the meandering network of posterolateral spinal arteries and the continuous ventral midline anterior spinal artery. Anatomic dissections have shown the anterior spinal artery to be continuous along the whole length of the spinal cord by anatomic dissections, although by angiographic x-ray examination the artery may sometimes erroneously appear discontinuous. The study by Koshino and colleagues ${ }^{4}$ confirms, on the basis of anatomic grounds, that the size of the segmental intercostal or lumbar arteries has no correlation either as to which specific artery the arteria radicularis magna (ARM, the artery of Adamkiewicz) arises from or to the size of the ARM per se. These observations are not unexpected, because the ARM is small (in our study, ${ }^{3} 0.941 \mathrm{~mm}$; in Koshino and colleagues' study, ${ }^{4} 0.77 \mathrm{~mm}$ ), in comparison with the size of the segmental arteries $(2.8 \mathrm{~mm}){ }^{4}$ Indeed, the size of the segmental arteries appears to be more dependent on the muscle bulk supplied on either the chest or abdominal wall. Clearly, the size of the segmental artery ostia in the aorta, or the amount of backflow from the ostia during aortic surgery, has no bearing on the ARM or any other major radicular artery arising and being supplied by the particular segmental artery. Thus a com- mon misunderstanding, based on the faulty premise that the largest segmental ostia with the most backflow need to be reattached to reestablish spinal cord blood flow, may result in inadequate reperfusion of the spinal cord. Therefore reattaching only these vessels, which may not supply the spinal cord, at the time of descending thoracic or thoracoabdominal repairs is fraught with the risk of not adequately reestablishing the spinal cord blood supply. Of relevance, ligation of only the ARM before it joins the anterior spinal artery both in nonhuman primate studies and in porcine studies results in a high paraplegia rate $(50 \%-100 \%$ and $71.4 \%$, respectively). ${ }^{1}$

The anatomy of the ARM and thoracic radicular arteries and their junction with the anterior spinal artery are critical to understanding blood flow patterns during repairs on the descending and thoracic or thoracoabdominal aorta, particularly when using distal aortic perfusion. In the course of performing an impressive number of spinal cord dissections ( $>100$ performed), it is unfortunate that Koshino and colleagues ${ }^{4}$ did a posterior laminectomy rather than an anterior removal of the vertebral bodies. Had they used the latter method, they might have further confirmed our findings in 8 human spinal dissections and some 60 in the chacma baboon. Our dissections invariably showed that the ARM joins the anterior spinal artery at an acute angle and then takes a well-described hairpin bend to join the more caudally directed anterior spinal artery. The anterior spinal artery is characteristically diminutive above this junction ( $0.231 \mathrm{~mm}$ in our study) in human beings and considerably larger below the junction $(0.941 \mathrm{~mm}$ in our study, $P=.0057) .^{1,3,5}$ The importance of this finding is that during an aortic repair, perfusion of segmental arteries supplying the ARM results in perfusion of the caudal spinal cord below the junction of the ARM. On the basis of our calculations by Poiseuille's equation, resistance was 278 times greater up the anterior spinal artery. This pattern of anatomy and blood flow was confirmed by our radioactive microsphere blood flow studies in nonhuman primates. ${ }^{5}$ Similarly, only reattachment of the ARM and more caudal segmental lumbar arteries should protect the lumbar spinal cord, but may leave the lower thoracic spinal cord in jeopardy. In contrast to the ARM, thoracic radicular arteries join the anterior spinal artery end to side and perfuse the spinal cord both cranially and caudally. Thus distal aortic perfusion and also reattachment of these arteries ensure better protection of the thoracic spinal cord, particularly when a large lower thoracic spinal cord radicular artery is present, as is often the case and as Koshino and colleagues have also 
noted. ${ }^{1,3,4}$ (It should be noted that they defined the ARM by size and not by the characteristic junction with the anterior spinal artery; hence duplicate "Adamkiewicz arteries" were recorded.) It is important to understand, however, that because of the longitudinal nature of the anterior spinal artery and the posterolateral spinal arteries, collateral supply to the spinal cord from distant sources, for example, the cervical radicular arteries or vertebral arteries, may often be sufficient to maintain spinal cord viability in the thoracic segment, even if all the thoracic radicular arteries are occluded or oversewn.

How then should segmental arteries be managed during operative repairs of the descending or thoracoabdominal aorta with our current level of knowledge? For repairs of the proximal and mid-descending aorta, reimplantation of segmental arteries does not, in my opinion, appear to be critical, as has also been discussed by Griepp and colleagues. ${ }^{6}$ We have evaluated and mapped the spinal cord blood supply with hydrogen and found that only about 1 in 4 patients with aneurysms had vessels from this segment supplying the spinal cord. Furthermore, insertion of stents that occlude intercostal arteries in this segment can be safely placed. However, for repairs of the distal descending aorta, ${ }^{1,4}$ particularly beyond $\mathrm{T} 8,{ }^{9}$ the risk of spinal cord injury is statistically increased by graft replacement without reimplantation of segmental arteries or by stent graft placement. ${ }^{1,6-9}$ Nevertheless, most patients may have no harmful effect. ${ }^{1,6-9}$ By contrast, however, I believe reimplantation of segmental arteries is vital for Crawford type I and type II thoracoabdominal aneurysms. In such operations, a large number of segmental arteries arise from the aorta to be repaired, and there have been careful studies to evaluate the influence of patency of segmental arteries and whether they were reattached or not as to the risk of neurologic injury. ${ }^{8-12}$ These reports have clearly shown a significantly higher risk of spinal cord injury with failure to reattach patent segmental arteries. ${ }^{8-12}$ In our study, ${ }^{10}$ this was particularly so for failing to reattach patent segmental arteries in the T10-L1 segment. With these more extensive repairs, Griepp and colleagues ${ }^{6}$ also found that the larger the number of segmental arteries that were sacrificed, the greater the risk of spinal cord injury.

On the basis of our studies and our understanding of the spinal cord vascular anatomy, we have in the past (since 1986) recommended a general rule of thumb that all intercostal lumbar arteries including T7 down to L1 should be reattached. ${ }^{1-3,7,10}$ This general approach has the advantage of most likely perfusing both the ARM (and the lumbar spinal cord) and the lower thoracic radicular arteries (and the lower thoracic spinal cord). Koshino and colleagues have used this approach with some success. In my view, the problems with the T7-L1 operative strategy are as follows: (1) Reattaching all these arteries from $\mathrm{T} 7$ to L1 prolongs the crossclamping time, and the latter has been the best predictor of spinal cord injury; (2) some of the arteries that are reattached may not need to be reattached, although they may contribute to collateral blood flow. Obviously, an accurate and reliable technique for identifying those arteries that need to be reattached should be the goal. Thus far, various experimental methods have been described, such as preoperative spinal cord angiography, intraoperative somatosensory evoked potential monitoring, and the techniques we have used of spinal cord motor-evoked potential monitoring and hydrogen or oxygen mapping. ${ }^{1}$ The main drawback of these techniques, so far, is that they are complicated and, hence, time consuming. If any one of these methods can be refined to the degree that they are simple to apply, reliably accurate, and sensitive, then one or more will become clinically applicable. Our early experience with hydrogen mapping suggested that the aortic crossclamp time may be shortened in some patients with this method. ${ }^{7}$ In the meantime, reattaching all intercostal arteries from $\mathrm{T} 7$ to $\mathrm{L} 1$ and adjunctive protective methods (distal perfusion, hypothermia, intrathecal papaverine, cerebrospinal fluid drainage, mild postoperative hypertension) have resulted in a lower risk of paraplegia; thus only $2.9 \%$ of our recent 74 patients undergoing descending or thoracoabdominal repairs were unable to walk after the operation. Others ${ }^{8,11,12}$ have adopted this rule of thumb, including Coselli and colleagues, who recently reported their experience with 1220 thoracoabdominal repairs at the January 1999 meeting of The Society of Thoracic Surgery, with an overall incidence of spinal cord injury of $4.6 \%$.

Lars Svensson, $M D, P h D$ Burlington, Mass

\section{REFERENCES}

1. Svensson LG, Crawford ES. Cardiovascular and vascular disease of the aorta. Philadelphia: WB Saunders; 1997.

2. Svensson LG, Crawford ES, Hess KR, Coselli JS, Safi HJ. Experience with 1509 patients undergoing thoracoabdominal aortic operations. J Vasc Surg 1993;17:357-70.

3. Svensson LG, Klepp P, Hinder RA. Spinal cord anatomy of the baboon: comparison with man and implications on spinal cord blood flow during thoracic aortic cross-clamping. S Afr J Surg 1986;24:32-4

4. Koshino T, Murakami G, Morishita K, Mawatari T, Abe T. Does the Adamkiewicz artery originate from the larger segmental arteries? J Thorac Cardiovasc Surg 1999;117:898-905.

5. Svensson LG, Rickards E, Coull A, Rogers G, Fimmel CJ, 
Hinder RA. Relationship of spinal cord blood flow to vascular anatomy during thoracic aortic crossclamping and shunting. J Thorac Cardiovasc Surg 1986;91:71-8.

6. Griepp RB, Ergin MA, Galla JD, Lansman S, Khan N, Quintana $\mathrm{C}$, et al. Looking for the artery of Adamkiewicz: a quest to minimize paraplegia after operations for aneurysm of the descending thoracic and thoracoabdominal aorta. J Thorac Cardiovasc Surg 1996;112:1202-13.

7. Svensson LG. Intraoperative identification of spinal cord blood supply during descending and thoracoabdominal aortic repairs. J Thorac Cardiovasc Surg 1996;112:1455-61.

8. Coselli JS. Thoracoabdominal aortic aneurysms: experience with 372 patients. J Card Surg 1994;9:638-47.

9. Borst HG, Jurnmann M, Buhner B, Lass J. Risk of replacement of descending aorta with a standardized left heart bypass technique. J Thorac Cardiovasc Surg 1994;107:126-32.

10. Svensson LG, Hess KR, Coselli JS, Safi HJ. Influence of segmental arteries, extent, and atriofemoral bypass on postoperative paraplegia after thoracoabdominal aortic operations. J Vasc Surg 1994;20:255-62.

11. Mauney MC, Tribble CG, Cope JT, Tribble RW, Luctong A, Spotnitz WD, Kron IL. Is clamp and sew still viable for thoracic aortic resection? Ann Surg 1996;223:534-40.

12. Safi HJ, Miller CC III, Carr C, Iliopoulous DC, Dorsay DA, Baldwin JC. Importance of intercostal artery reattachment during thoracoabdominal aortic aneurysm repair. J Vasc Surg 1998; 27:58-66.

$12 / 1 / 98072$

\section{ON THE M OVE?}

Send us your new address at least six weeks ahead

Don't miss a single issue of the journal! To ensure prompt service when you change your address, please photocopy and complete the form below.

Please send your change of address notification at least six weeks before your move to ensure continued service. We regret we cannot guarantee replacement of issues missed due to late notification.

\section{JOURNAL TITLE:}

Fill in the title of the journal here.

\section{OLD ADDRESS:}

Affix the address label from a recent issue of the journal here.
NEW ADDRESS:

Clearly print your new address here.

Name

Address

City/State/ZIP

\section{COPY AND MAIL THIS FORM TO:}

Periodical Subscription Services

Mosby, Inc.

11830 Westline Industrial Dr.

St. Louis, MO 63146-3318
OR FAX TO:

314-432-1158

N/ Mosby

\section{OR PHONE:}

1-800-453-4351

Outside the U.S., call

314-453-4351 